\title{
Basic fibroblast growth factor increases the transplantation-mediated therapeutic effect of bone mesenchymal stem cells following traumatic brain injury
}

\author{
YANG LIU $^{1,2^{*}}$, XI-CAI YI ${ }^{2 *}$, GENG GUO ${ }^{3 *}$, QIAN-FA LONG ${ }^{2 *}$, XIAO-AN WANG ${ }^{2 *}$, \\ JUN ZHONG ${ }^{2}$, WEI-PING LIU ${ }^{2}$, ZHOU FEI ${ }^{2}$, DONG-MEI WANG ${ }^{1}$ and JUN LIU ${ }^{4}$
}

${ }^{1}$ Department of Neurosurgery, The Third Hospital of Mianyang, Mianyang, Sichuan 621000; ${ }^{2}$ Department of Neurosurgery, Xijing Hospital, Fourth Military Medical University, Xi'an, Shaanxi 710032; ${ }^{3}$ Department of Neurosurgery, The First Hospital of Shanxi Medical University, Taiyuan, Shanxi 030001; ${ }^{4}$ Department of Neurosurgery, Xinqiao Hospital, The Third Military Medical University, Chongqing 400037, P.R. China

Received April 20, 2013; Accepted October 15, 2013

DOI: $10.3892 / \mathrm{mmr} .2013 .1803$

\begin{abstract}
Basic fibroblast growth factor (bFGF) has proven useful for neural stem and progenitor cells during the transplantation-mediated therapeutic effect of bone mesenchymal stem cells (BMSCs). Endogenous bFGF expression levels increase during brain development and gradually diminish with aging. To date, few studies have been conducted on exogenous bFGF promoting BMSC transplantation-mediated functional recovery in adult rats following traumatic brain injury (TBI). The results of the present study showed that BMSCs in the TBI cortex and dentate gyrus showed differentiation along the glial and neuronal lines, which are possibly enhanced by bFGF. The neuronal differentiation rate was not consistent with neurological functional recovery rate over time. bFGF may promote the transplantation-mediated therapeutic effect of BMSCs more significantly and rapidly in rats following TBI, with a small proportion of differentiated neurons. In conclusion, exogenous bFGF functions as a booster of the transplantation-mediated therapeutic effect of BMSCs following TBI.
\end{abstract}

\section{Introduction}

Bone mesenchymal stem cells (BMSCs) have been shown to exhibit the ability to improve the neurological functional outcome of central nervous system (CNS) disorders, including stroke and traumatic brain injury (TBI) $(1,2)$. Moreover, BMSCs are capable of proliferating and differentiating into neurons and

Correspondence to: Dr Jun Liu, Department of Neurosurgery, Xinqiao Hospital, The Third Military Medical University, No. 83 Zheng Street, Shapingba, Chongqing 400037, P.R. China

E-mail: JUNLIUCN@126.com

*Contributed equally

Key words: basic fibroblast growth factor, bone mesenchymal stem cells, traumatic brain injury, transplantation glial cells in vivo and in vitro $(3,4)$. These studies affirm BMSCs as a potential candidate for use in cellular therapy for CNS disorders. However, this type of therapy presents difficulties in the treatment of brain injury due to the limited plasticity of the nervous system and the complicated pathological processes involved. The viability of transplanted stem cells may be reduced in in vivo conditions, including a low-oxygen environment or during an immunoreaction. Moreover, neurotrophic factors are imperative for tissue regeneration as an insufficient level of neurotrophins weakens the proliferation and differentiation of transplanted stem cells (5). Thus, increasing the viability of grafts through the utilization of neurotrophic factors is an important strategy in promoting the efficacy of cell therapy for the treatment of CNS diseases. Among a large number of neurotrophic factors, the basic fibroblast growth factor (bFGF) has been shown as a potent mitogen for neural stem and progenitor cells in vitro and in vivo. Evidently, bFGF fulfills a mediative function in inducing neurogenesis (6) and enhancing neural survival and outgrowth (7). Furthermore, bFGF alone has been demonstrated to induce BMSC neuronal differentiation effectively in vitro (8). However, endogenous bFGF expression levels diminish with aging but increase during brain development $(9,10)$. Thus, BMSC-derived neural functional recovery may be promoted through the administration of exogenous bFGF following various brain injuries in the adult mammal. To date, few studies have been conducted on exogenous bFGF promotion of BMSC transplantation-mediated functional recovery in adult rats following TBI. The current study was performed to investigate the therapeutic potential of exogenous bFGF to promote BMSC transplantation for adult brain repair, as well as to examine the effects of bFGF on BMSC transplantation in adult rats following TBI.

\section{Materials and methods}

Animals. A total of 48 male Sprague-Dawley rats (age, 3 months; weight, $300 \mathrm{~g}$ ) were obtained from the Experimental Animal Center, Fourth Military Medical University (Xi'an, China) to be used in the present study. This study was conducted 
in strict accordance with the recommendations in the Guide for the Care and Use of Laboratory Animals of the National Institutes of Health (1996). The animal use instructions were reviewed and approved by the Institutional Animal Care and Use Committee of the Fourth Military Medical University. Rats were divided into four groups: $A,(n=6)$ rats without TBI; $\mathrm{B},(n=6)$, rats with TBI that underwent no treatment; $C,(n=18)$ TBI group treated with BMSC transplantation and D, $(n=18)$ TBI group treated with BMSC transplantation and bFGF.

Cultivation of BMSCs. BMSCs were isolated and cultured according to a typical method (11) with modifications. Briefly, bone marrow was harvested from the femurs and tibias of one month-old male Sprague-Dawley rats through suction using a $20 \mathrm{ml}$ sterile syringe. For anticoagulation, $5 \mathrm{ml}$ heparin (100 IU/ml) was used. The recovery of the nucleated cells was accomplished by centrifugation at $900 \mathrm{x}$ g. BMSCs $\left(<4 \times 10^{5}\right)$ were loaded into $3 \mathrm{ml}$ Percoll (Sigma, St. Louis, MO, USA) with a density of $1.089 \mathrm{~g} / \mathrm{ml}$, in a $15 \mathrm{ml}$ conical tube. The cells were separated following centrifugation at $1,100 \mathrm{x} \mathrm{g}$ for $20 \mathrm{~min}$ at $20^{\circ} \mathrm{C}$. The primary BMSCs were cultured in flasks at $2 \times 10^{5}$ cells $/ \mathrm{ml}$ with Dulbecco's modified Eagle's medium (DMEM) F12 (Gibco-BRL, Carlsbad, CA, USA) containing $15 \%$ fetal bovine serum (Hyclone, Logan, UT, USA) in a carbon dioxide incubator $\left(37^{\circ} \mathrm{C}, 5 \% \mathrm{CO}_{2}\right)$. The medium was replaced every three days. When adherent cells reached $\sim 80 \%$ confluency, the cells were propagated to the next passage. Following three passages of culture and identification by flow cytometry (Biomedika Instruments Inc., Dollard-des-Ormeaux, QC, Canada), BMSCs were ready for analysis and transplantation by trypsinization using $0.25 \%$ trypsin and $0.02 \%$ EDTA.

Labeling of BMSCs with bromodeoxyuridine (BrdU). When the cells had reached $60 \%$ confluency, rat BMSCs were labeled with BrdU (Sigma) at $3 \mu \mathrm{g} / \mathrm{ml}$ concentration by the addition of BrdU to the culture and the mixture was incubated for two days. Following washing three times with sterile phosphate-buffered saline (PBS), the BMSCs were trypsinized and used in subsequent in vivo experiments.

TBI model. The TBI model was developed as described in a previous study (12) with modifications. Following administration of chloral hydrate (Kangjie Technology and Development Co., Ltd., Wuhan, China) anesthesia $[300 \mathrm{mg} / \mathrm{kg}$, intraperitoneally (i.p.)], the scalps were incised and a bone window was developed over the right forelimb motor cortex. Specifically, the rats were placed into a stereotactic frame (Wandong Instruments, Ltd., Wuhan, China). The center of the bone window was $2.5 \mathrm{~mm}$ lateral to the midline and $1.5 \mathrm{~mm}$ posterior to the bregma. The diameter of the bone window was $5.0 \mathrm{~mm}$. The bone was thinned over the right forelimb motor cortex using a high-speed microdrill (Ruijing Medical Equipment Co., Ltd., Wuhu, China) and the last layer of the bone was removed with forceps. A $40 \mathrm{~g}$ weight was inserted into the top of the tube $(25 \mathrm{~cm})$ and was allowed to slide through the tube to deliver a blow onto the motor cortex to induce TBI. The bone flap was placed in situ following TBI, without fixing.

Surgical procedures. One day following TBI modeling, the rats were anesthetized using chloral hydrate $(300 \mathrm{mg} / \mathrm{kg}$, i.p.) and were placed into a stereotactic frame (Wandong Instruments, Ltd.) for the microinjection procedure. Prior to transplantation, BMSCs were digested with trypsin, washed twice with DMEM and centrifuged. The BMSCs were diluted in PBS at a density of $1 \times 10^{5}$ cells $/ \mu 1$. A microinjector was slowly inserted $4 \mathrm{~mm}$ vertically through a hole drilled on the skull into the right lateral ventricle of each animal. The microinjections were conducted at a rate of $1 \mu \mathrm{l} / \mathrm{min}$. BMSCs $\left(1 \times 10^{6}\right.$ cells $\left./ \mu \mathrm{l}\right)$ were unilaterally implanted into the left lateral ventricle of the rats. Groups C and D received BMSC infusions, whereas groups A and $\mathrm{B}$ received a normal saline infusion. The needle was left in place for an additional $10 \mathrm{~min}$ prior to being slowly drawn back. Following TBI, this intralateroventricular injection of bFGF solution (PeproTech, Rocky Hill, NJ, USA) was performed for seven consecutive days (400 ng/day). Group D received a bFGF infusion, whereas groups $\mathrm{A}, \mathrm{B}$ and $\mathrm{C}$ received a normal saline infusion. The needle was kept in the targets for a further $5 \mathrm{~min}$ prior to being slowly withdrawn. Six rats from groups C and D at days 10 and 20 post-TBI, respectively and six from groups $A$ and $\mathrm{B}$, in addition to the remainder of groups $\mathrm{C}$ and $\mathrm{D}$ at day 30 post-TBI, were euthanized by intraperitoneal injection of pentobarbital natrium and perfused with $4 \%$ paraformaldehyde.

Immunohistochemical staining. Immunohistochemical staining was performed by BrdU labeling to identify the transplanted BMSCs. Formalin-fixed and paraffin-embedded brain tissue blocks were sliced into $4-\mu \mathrm{m}$ thick sections. The sections were deparaffinized in xylene, followed by rehydration in a decreasing concentration gradient of ethanol solution. The sections were subjected to microwave heat-induced epitope retrieval in boiled EDTA for 2 min. Following washing with $0.1 \mathrm{M}$ PBS, these sections were pretreated with $0.3 \% \mathrm{H}_{2} \mathrm{O}_{2}$ in methanol for $30 \mathrm{~min}$ at room temperature to prevent endogenous peroxidase activity. The sections were then blocked with PBS, 3\% skimmed milk and 3\% normal donkey serum for $2 \mathrm{~h}$ at room temperature and anti-BrdU (sheep, 1:200; Abcam, Cambridge, MA, USA) was applied onto the sections, which were subsequently incubated for $24 \mathrm{~h}$ at $4^{\circ} \mathrm{C}$ in a humidified chamber. Following rinsing with PBS with Tween-20, the samples were reacted with biotinylated secondary antibody (Donkey anti-sheep IgG, 1:500; Abcam Inc., Cambridge, MA, USA) diluted in $0.1 \mathrm{M}$ PBS (1:500) for $2 \mathrm{~h}$ at room temperature. Subsequently, these sections were incubated with an avidin-biotin peroxidase complex (Sigma) diluted in 0.1 M PBS (1:500) for $2 \mathrm{~h}$ at room temperature. The samples were developed in a staining solution (DAB). All steps were performed according to the manufacturer's instructions. The sections were examined under a light microscope, (Carl Zeiss, Oberkochen, Germany). To confirm whether the staining satisfactorily developed, cells were counterstained with hematoxylin to facilitate the visualization of the immunostained product. In addition, non-immune serum was used in the controls for the primary antibodies or omission of the primary antibodies.

Immunofluorescent double-labeling. Double-immunostaining with immunofluorescence was performed. The parallel sections were processed for immunofluorescent double labeling with antibodies against BrdU and markers for mature neurons (NeuN) and astrocytes (glial fibrillary acidic protein, GFAP). The staining procedure used was similar to the BrdU staining 
procedure described in the previous section with modifications. The primary antibodies used were mouse anti-NeuN (1:500, Millipore, Billerica, MA, USA), mouse anti-GFAP (1:500, Millipore) and sheep anti-BrdU (1:500, Abcam). Secondary antibodies used were Alexa Fluor 488 anti-mouse IgG (1:500, Millipore) or Cy3-conjugated anti-goat IgG (1:500, Chemicon, Temecula, CA, USA). Sections in EDTA buffer were boiled in a microwave for $2 \mathrm{~min}$ to retrieve the antigen. Following DNA denaturation, endogenous peroxidase and serum blocking, sections were incubated with primary antibodies for $48 \mathrm{~h}$ at $4^{\circ} \mathrm{C}$ with constant shaking. Following washing three times, sections were incubated with secondary antibodies for $4 \mathrm{~h}$ at room temperature. Vectashield cover slips (Kangjie Technology and Development Co., Ltd.) were placed on the slides, which were examined using an Olympus BX51 fluorescent microscope (Olympus, Tokyo, Japan).

Quantification of cells. Sections were examined using an Olympus Image System CAST program (Olympus BX-51) to quantify the number of BrdU-positive cells in the dentate gyrus (DG) and cortex. Results are expressed as the average number of cells per specimen in the target areas that consist of the DG and cortex. Eight sections per sample at the level of DG spanning between -2.56 and $-5 \mathrm{~mm}$ of bregma and eight sections per sample at the level of TBI cortex spanning between -1 and $-2 \mathrm{~mm}$ of bregma were assessed by a blinded pathologist. All BrdU-positive cells in the DG and TBI cortex were counted regardless of size or shape under magnification $\mathrm{x} 200$. These immunofluorescent double-labeling slides were examined using an Olympus fluorescent microscope to quantify the number of BrdU-positive cells that had differentiated to the varying cell types. In counting the double-stained sections, all BrdU-labeled cells, which were located in the DG and cortex, were examined for colocalization with NeuN or GFAP in sections. Only those cells for which the BrdU-positive cells were unambiguously associated with a specific cell type-specific marker were considered to be double-labeled. Immunofluorescent double-labeled images were imported into Photoshop under magnification x200 (Olympus BX-51) for merging and the number of BrdU-positive cells (red fluorescence image) which colocalized with NeuN or GFAP (green fluorescence image) was counted on a computer monitor.

Neurological functional evaluation. All tests began at 5:00 pm, following the nocturnal habits of rats. Beginning on the day following TBI modeling, continuing every 10th day thereafter for one month and prior to euthanasia, animals were examined using two standard tests to assess the sensorimotor function in the limbs, as well as vestibulomotor function (13). Specifically, the forelimb placing test measures sensorimotor function in each forelimb as the animal places the limb on a tabletop in response to visual, tactile and proprioceptive stimuli (total score $=0-10 ; 10=$ maximally impaired) (13). The modified beam balance test examines vestibulomotor activity as the animal balances on a narrow beam $(30 \times 1.3 \mathrm{~cm})$ for $60 \mathrm{sec}$ (score range $=1-7 ; 7=$ maximally impaired) (13).

Statistical analyses. All statistical analyses were performed using SPSS ${ }^{\circledR}$ version 16.0 software (SPSS Inc., Chicago, IL, USA). One-way analysis of variance and the Bonferroni test were used to compare the differences between three or four groups and groups in pairs, respectively. The t-test was used to compare the differences between those in the contralateral hemisphere and those in the ipsilateral hemisphere. $\mathrm{P}<0.05$ was considered to indicate a statistically significant difference.

\section{Results}

The majority of BrdU-labeled cells were identified in the injured hemisphere concentrated around the contusion cortex and the DG, whereas the minority were located in the contralateral hemisphere (Fig. 1). In group D, immunofluorescent doublelabeling showed the highest expression of astrocytes and neuron markers, with a small differentiation proportion $(\mathrm{P}<0.05$; Fig. 2A-I; Fig. 3E-H). The majority of BMSCs in the TBI cortex and DG showed differentiation along the glial line, which was possibly enhanced by bFGF (Fig. 2J-R; Fig. 3G-H). Statistical significance was observed in the number of BrdU-positive cells in the ipsilateral DG and cortex between groups $\mathrm{C}$ and $\mathrm{D}$ at 10 , 20 and 30 days post-injury ( $P<0.05$; Fig. 3 C-D). The trend in the ipsilateral DG in groups $\mathrm{C}$ and $\mathrm{D}$ was towards the significant increase in the number of mitotically BrdU-positive cells immediately following injury, which decreased marginally 20 days post-injury $\left(\mathrm{F}_{\mathrm{C}}, 26.182 ; \mathrm{F}_{\mathrm{D}}, 26.524 ; \mathrm{P}<0.05\right.$; Fig. 3C). The same results were observed for groups $\mathrm{C}$ and $\mathrm{D}$ in the ipsilateral cortex $\left(\mathrm{F}_{\mathrm{C}}, 22.962 ; \mathrm{F}_{\mathrm{D}}, 12.180 ; \mathrm{P}<0.05 ;\right.$ Fig. 3D).

The peak increase in the neuronal differentiation rate in the $\mathrm{DG}$ occurred 20 days post-injury in groups $\mathrm{C}$ and $\mathrm{D}\left(\mathrm{F}_{\mathrm{C}}\right.$, 5.91; $\mathrm{F}_{\mathrm{D}}, 26.882 ; \mathrm{P}<0.05 ; \mathrm{Fig}$. 3E). In the ipsilateral cortex, the same results were observed for groups $\mathrm{C}$ and $\mathrm{D}\left(\mathrm{F}_{\mathrm{C}}, 7.562 ; \mathrm{F}_{\mathrm{D}}\right.$, 35.192; $\mathrm{P}<0.05$; Fig. 3F).

A statistically significant improvement was observed in the forelimb placing test scores $\left(\mathrm{F}_{\mathrm{C}}, 303.881 ; \mathrm{F}_{\mathrm{D}}, 456.813 ; \mathrm{P}<0.001\right.$; Fig. 3A), as well as in the modified beam balance test scores $\left(\mathrm{F}_{\mathrm{C}}\right.$, 111.825; $\mathrm{F}_{\mathrm{D}}, 281.817 ; \mathrm{P}<0.001 ;$ Fig. 3B). The recovery tempos of groups $\mathrm{B}$ and $\mathrm{C}$ were more rapid in the first 20 days $(\mathrm{P}<0.001)$, gradually decreasing for the remainder of the study period, as evidenced in the forelimb placing $\left(\mathrm{P}_{\mathrm{B}}, 0.426 ; \mathrm{P}_{\mathrm{C}}, 0.512\right.$; Fig. 3A) and modified beam balance test scores $\left(\mathrm{P}_{\mathrm{B}}, 0.623 ; \mathrm{P}_{\mathrm{C}}\right.$, 0.474; Fig. 3B). At a different time point, group D constantly showed the most significant improvement, which is inconsistent with the neuronal differentiation rate, as demonstrated in the recovery of the forelimb placing $\left(\mathrm{F}_{10}, 224.626 ; \mathrm{F}_{20}, 67.216 ; \mathrm{F}_{30}\right.$, 93.925; $\mathrm{P}<0.001$; Fig. $3 \mathrm{~A})$ and modified beam balance tests $\left(\mathrm{F}_{10}\right.$, 110.009; $\mathrm{F}_{20}, 48.110 ; \mathrm{F}_{30}, 41.961 ; \mathrm{P}<0.001 ;$ Fig. 3B).

\section{Discussion}

Currently available engrafted stem cells are primarily classified into two types: Neural and non-neural stem cells. As non-neural stem cells, BMSCs have an advantage over neural and embryonic stem cells, which are more difficult to prepare and culture and are limited in availability. Notably, the utilization of BMSCs does not create ethical issues. In the current study, the lower survival rate of the grafted cells is attributed to the shortage of neurotrophic support due to the occurrence of numerous newly engrafted cells and/or to the less conducive environment for cell survival due to injury. However, the current results indicate that following transplantation, cells survive in vivo for at a minimum of one month even without bFGF treatment. 

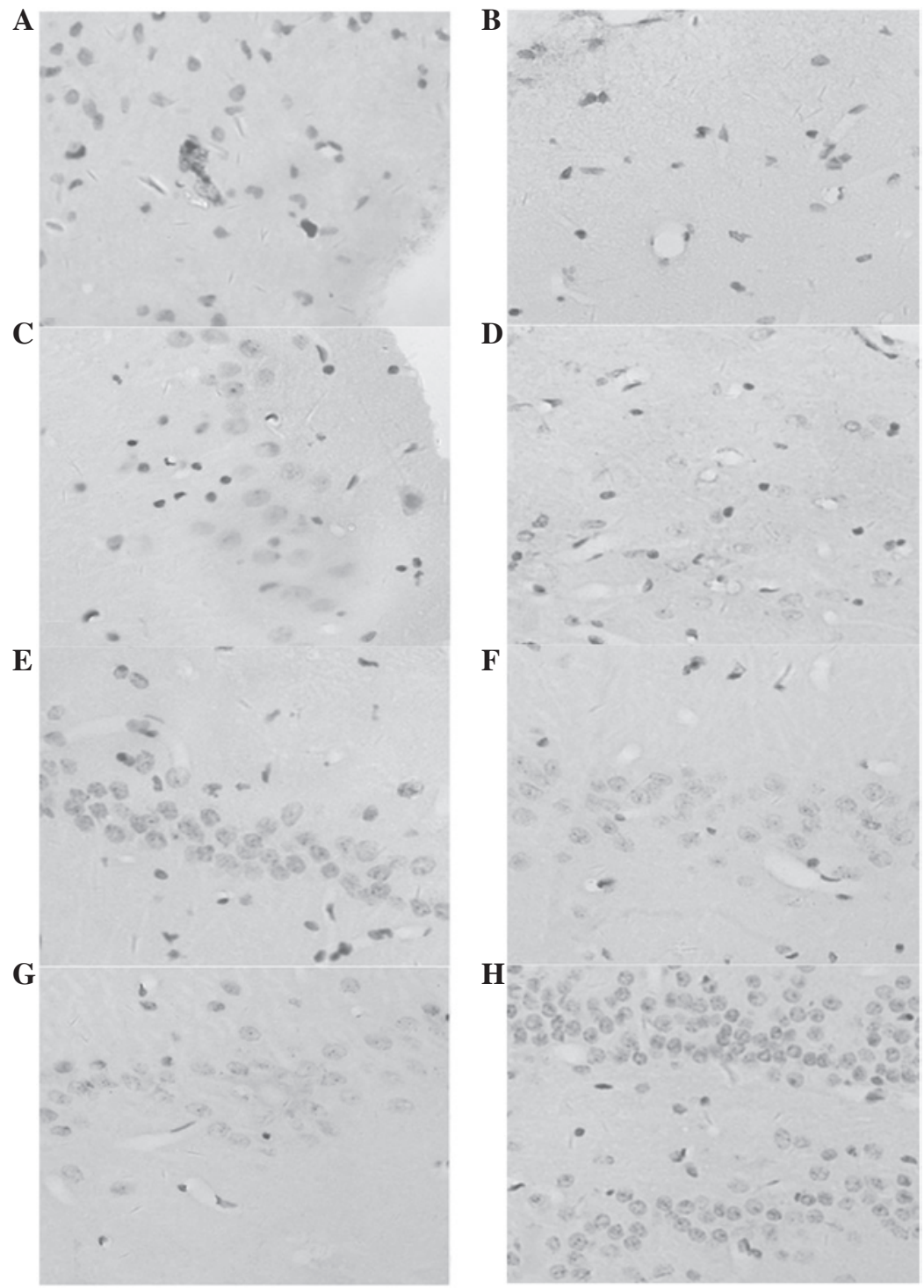

Figure 1. BMSC distribution in the DG and cortex following TBI. Immunohistochemistric images at four weeks following TBI show BrdU ${ }^{+}$cells in the DG and cortex. (A) BrdU $\mathrm{B}^{+}$cells in the contralateral cortex of the BMSC group; (B) BrdU ${ }^{+}$cells in the ipsilateral cortex of the BMSC group; (C) BrdU ${ }^{+}$cells in the contralateral cortex of the BMSC group with bFGF treatment; (D) BrdU ${ }^{+}$cells in the ipsilateral cortex of the BMSC group with bFGF treatment; (E) BrdU ${ }^{+}$ cells in the contralateral DG of the BMSC group; (F) BrdU+ cells in the ipsilateral DG of the BMSC group; $(\mathrm{G}) \mathrm{BrdU}^{+}$cells in the contralateral DG of the BMSC group with bFGF treatment and $(\mathrm{H}) \mathrm{BrdU}^{+}$cells in the ipsilateral DG of the BMSC group with bFGF treatment. BMSCs, Bone mesenchymal stem cells; DG, dentate gyrus; TBI, traumatic brain injury; BrdU, bromodeoxyuridine; bFGF, basic fibroblast growth factor.

bFGF is a mitogen for neuronal and non-neuronal stem cells, showing multifunctional and pleiotropic activities. Throughout the developmental stages and even in mature animals, bFGF provides important extracellular signals for regulating neurogenesis $(14,15)$. Furthermore, the beneficial effect of bFGF on functional recovery may be due to the increased connectivity (16). These results demonstrate that the survival, proliferation and differentiation of cells within the CNS are crucially dependent on signals provided by bFGF. In the present study, one of the essential contributions of bFGF in BMSCs transplantation therapy for TBI is the enhancement of the viability of transplanted cells. An increased viability of transplanted stem cells is indispensable for tissue regeneration. The therapeutic effect of BMSCs on the brain was evident in the current experiments. Moreover, the therapeutic effect may be further augmented with exogenous bFGF following TBI. Specifically, an intraventricular injection of bFGF immediately following TBI significantly increased the permeation of implanted cells into damaged areas, that is, the subventricular zone and the DG. Moreover, by determining the cell fate of these newly engrafted cells, the growth factor treatment generated more neurons and astrocytes than that identified in the group with injury alone or that which was induced with a vehicle infusion.

Based on previous studies, an extremely low percentage of differentiated neurons from transplanted cells were observed following transplanting stem cells into TBI models (17-19). Analogous results have been demonstrated in the present study. The proportion of differentiated neurons or astrocytes in this study was not significantly larger than those of previous studies. The question of whether a majority of BMSCs differentiate into neurons and astrocytes over time was also addressed. The possibility that, as time elapsed, an increased number of donor cells may present phenotypic markers of neurons and astrocytes, exists. The present data indicated that the number 

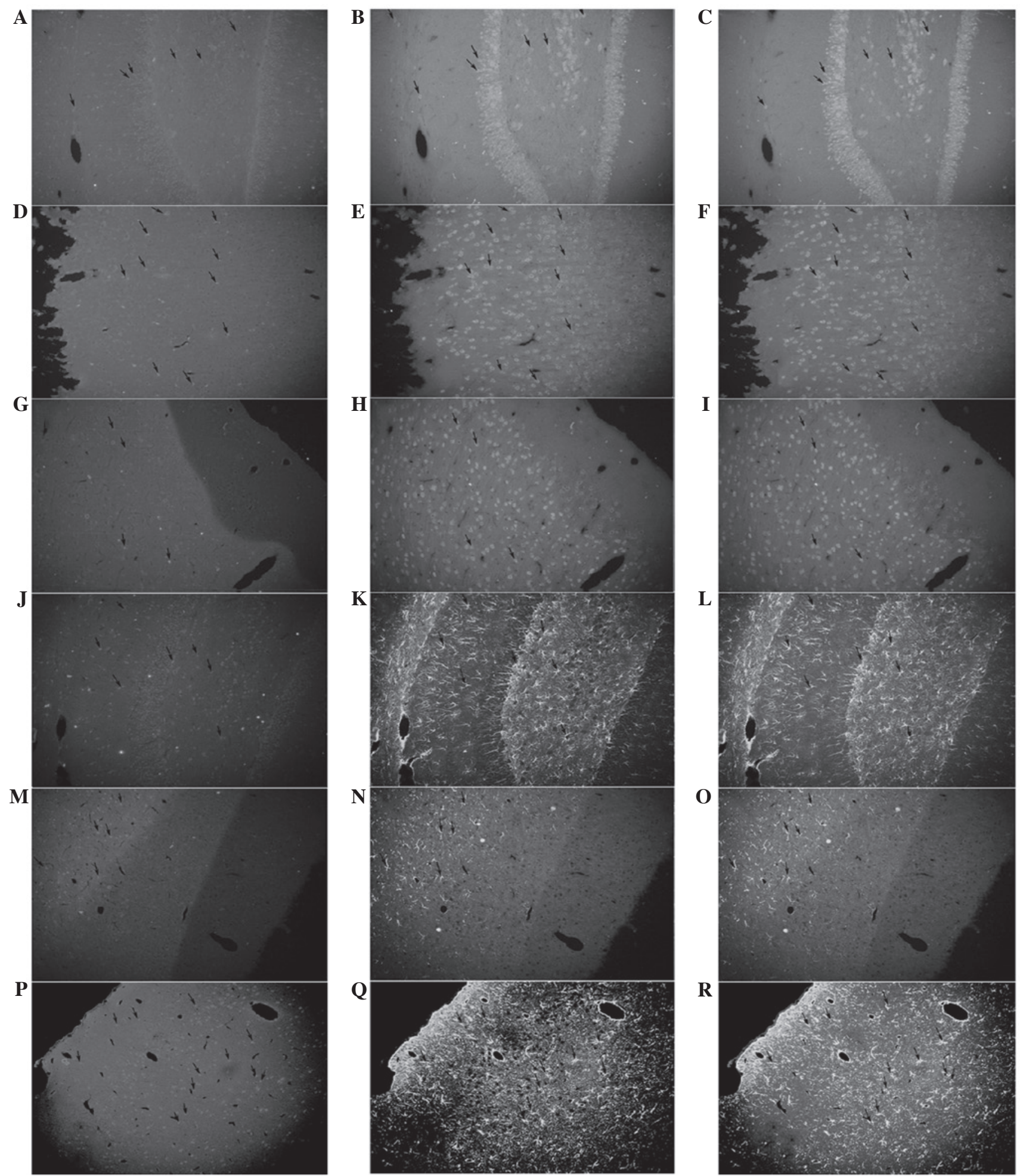

Figure 2. BMSCs in the DG and cortex differentiate into neurons and astrocytes following TBI. Immunofluorescent double-labeled images of the DG and cortex at four weeks following TBI showing double labeling of $\mathrm{BrdU}^{+}$cells with the neuronal marker NeuN and the astrocytic marker GFAP (A-R). Arrows indicate BrdU-positive cells (red), neuronal marker NeuN or astrocytic marker GFAP (green) and merged (yellow). (A-C) BrdU+-NeuN ${ }^{+}$in ipsilateral DG; (D-F) BrdU ${ }^{+}-\mathrm{NeuN}^{+}$in ipsilateral cortex; (G-I) BrdU ${ }^{+}-\mathrm{NeuN}^{+}$in contralateral cortex; (J-L) BrdU+-GFAP in ipsilateral DG; (M-O) BrdU+-GFAP ${ }^{+}$in contralateral cortex and (P-R) BrdU ${ }^{+}-G F A P^{+}$in ipsilateral cortex. BMSCs, Bone mesenchymal stem cells; DG, dentate gyrus; TBI, traumatic brain injury; BrdU, bromodeoxyuridine; GFAP, glial fibillary acidic protein

of donor cells expressing neuronal, astrocytic phenotypes was lesser at later time points compared with earlier time points. Rats under the effect of bFGF following TBI recovered most quickly. However, the neuronal differentiation rate was not consistent with the neurological functional recovery rate over time. The functional improvement in the present experiments may have resulted from the paracrine effect of the transplanted BMSCs or of bFGF itself, rather than from the neuronal differentiation of the transplanted stem cells. When the brain is damaged, reactions of neurotrophic factors may lead to 

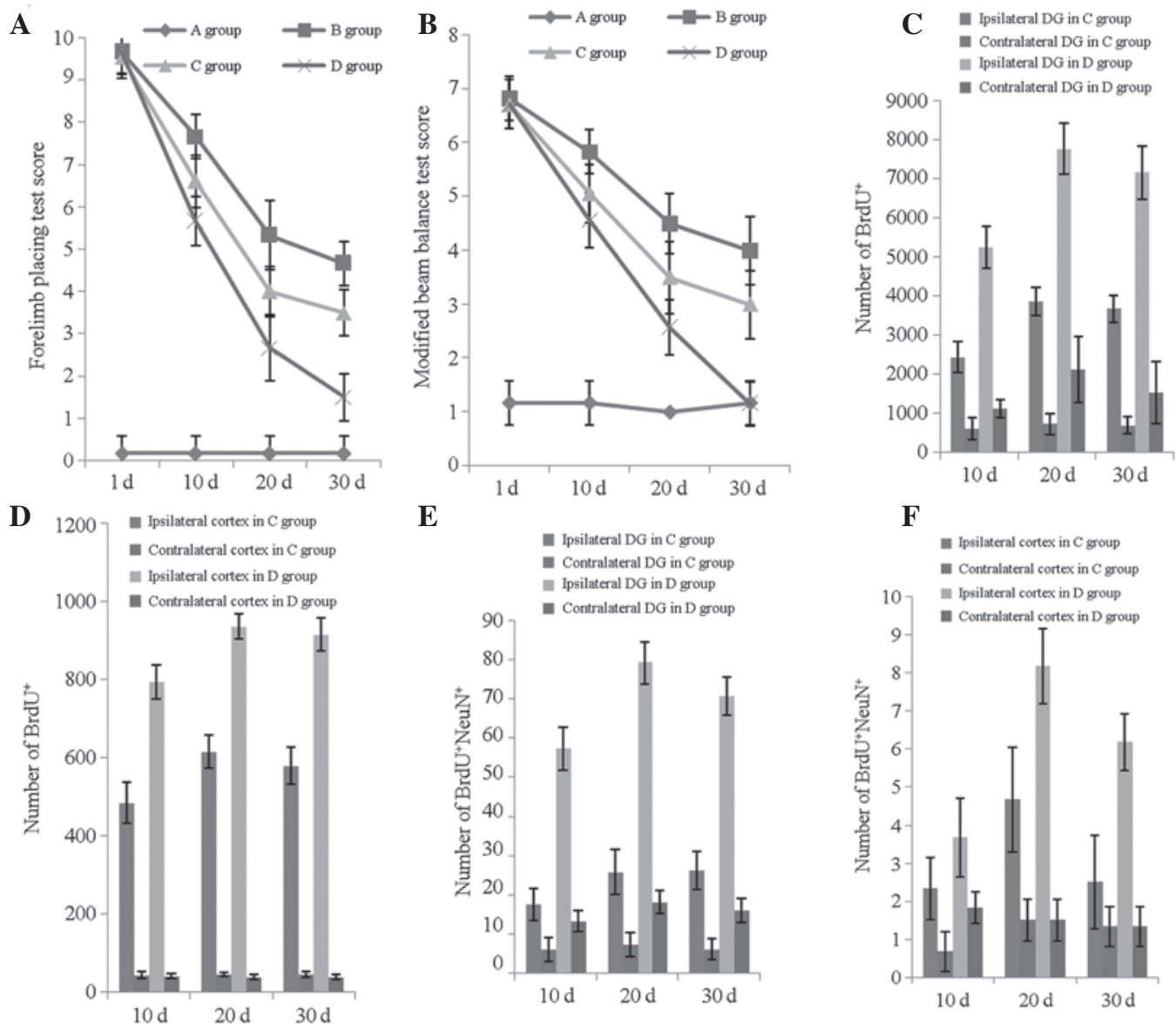

$\mathbf{E}$


Figure 3. Neurological functional evaluation and number of $\mathrm{BrdU}^{+} / \mathrm{NeuN}^{+} / \mathrm{GFAP}^{+}$cells at various time points. (A) Forelimb placing test scores of the four groups at 1,10,20 and 30 days post-TBI; (B) modified beam balance test scores of the four groups at 1, 10, 20 and 30 days post-TBI; (C) number of BrdU ${ }^{+}$cells in the ipsilateral and contralateral DG in groups $\mathrm{C}$ and $\mathrm{D}$ at 10,20 and 30 days post-TBI; (D) number of BrdU ${ }^{+}$cells in the ipsilateral and contralateral cortices in groups $\mathrm{C}$ and $\mathrm{D}$ at 10, 20 and 30 days post-TBI; (E) number of $\mathrm{BrdU}^{+} / \mathrm{NeuN}^{+}$cells in the ipsilateral and contralateral DG in groups $\mathrm{C}$ and $\mathrm{D}$ at 10, 20 and 30 days post-TBI; (F) number of $\mathrm{BrdU}^{+} / \mathrm{NeuN}^{+}$cells in the ipsilateral and contralateral cortices in groups $\mathrm{C}$ and $\mathrm{D}$ at 10,20 and 30 days post-TBI; (G) number of $\mathrm{BrdU}^{+} / \mathrm{GFAP}^{+}$cells in the ipsilateral and contralateral $\mathrm{DG}$ in groups $\mathrm{C}$ and $\mathrm{D}$ at 10,20 and 30 days post-TBI and $(\mathrm{H})$ number of $\mathrm{BrdU}^{+} / \mathrm{GFAP}^{+}$cells in the ipsilateral and contralateral cortices in groups $\mathrm{C}$ and $\mathrm{D}$ at 10,20 and 30 days post-TBI. Groups: A, rats without TBI; B, rats with TBI that underwent no treatment; C, TBI treated with transplantation of BMSCs; and D, TBI treated with transplantation of BMSCs and basic fibroblast growth factor. DG, dentate gyrus; TBI, traumatic brain injury; BrdU, bromodeoxyuridineBMSCs, bone mesenchymal stem cells.

changes in the surrounding brain tissue $(20,21)$. Specific gene expression becomes altered and a large number of potentially damaging and restorative neurochemical factors are released and upregulated. Such factors lead to delayed cellular dysfunction and death or tissue regeneration following brain injuries, including TBI (22). These neurotrophic factors may be the cause of the beneficial effect and may protect host neurons and facilitate the host regeneration observed in other stem cells, including neural stem cells $(23,24)$. Therefore, the beneficial effect of bFGF treatment on neural function may not be due to its protective function on the cyto-architecture, but rather due to other mechanisms. In the current experiments, the exogenous injection that maintains bFGF for an appropriate period enhanced bFGF efficacy for nerve regeneration, as the endogenous bFGF content is low in normal physical conditions, thus, following TBI, imbalance occurs. 
Although the present results provide certain reference values for the clinical utilization of BMSCs, further studies on this preliminary research are required. Following TBI, performing an immediate clinical administration is extremely difficult due to the short window of opportunity. One-day postinjury treatment, although clinically possible, may be difficult due to a significant portion of patients with severe head injury being transferred from smaller hospitals. For the majority of patients, moving from the smaller hospitals to the central hospitals would take more than a week. Hence, confirming the efficacy of BMSCs when administered at more than one time point following TBI, for example for one week or more, is essential. Furthermore, the treatment dosage (BMSCs and bFGF) at various time points following TBI also has a key function in affecting the outcome of BMSC transplantation. Previous results showed that a larger dose, specifically, $4 \times 10^{6} \mathrm{BMSCs}$, was required to be efficacious compared with the $2 \times 10^{6} \mathrm{BMSC}$ dose, which was effective when administered one day following injury (17-19). These observations are in agreement with those of other studies concerning neural injury. Methylprednisolone treatment administered within $3 \mathrm{~h}$ of spinal cord injury requires a shorter treatment (smaller total dose) to be efficacious than when initiated $3 \mathrm{~h}$ post-injury $(25,26)$. An intervention early in the injury phase requires less tissue repair than at later stages as damage from a neural injury does not simply occur at the time of injury, but is progressive and continues over time (27). To date, few studies regarding the correlation between the dosage, time windows, intervention and therapeutic effect of BMSCs have been conducted.

In conclusion, exogenous bFGF has become a booster for BMSC transplantation-mediated functional recovery following TBI, which has generated great interest in the neuroscience community. The results of the present study add to the understanding of the biological characteristics of cells with neurotrophic factors, and augments their potential for clinical utilization.

\section{Acknowledgements}

The authors would like to thank Ling Sun and Xiaoyan Chen for their assistance in this study. This study was funded by grants from the Foundation of Health Department Scientific Research Project in Sichuan Province (grant nos. 2010-100301 and 2011-110547), Mianyang City Health Bureau (grant no. 201102) and the Third Hospital of Mianyang (grant no. 2010-2012).

\section{References}

1. Li Y, Chen J, Chen XG, et al: Human marrow stromal cell therapy for stroke in rat: neurotrophins and functional recovery. Neurology 59: 514-523, 2002.

2. Lu D, Li Y, Mahmood A, Wang L, Rafiq T and Chopp M: Neural and marrow derived stromal cell sphere transplantation in a rat model of traumatic brain injury. J Neurosurg 97: 935-940, 2002.

3. Lu D, Li Y, Wang L, Chen J, Mahmood A and Chopp M: Intraarterial administration of marrow stromal cells in a rat model of traumatic brain injury. J Neurotrauma 18: 813-819, 2001.

4. Sanchez-Ramos J, Song S, Cardozo-Pelaez F, et al: Adult bone marrow stromal cells differentiate into neural cells in vitro. Exp Neurol 164: 247-256, 2000

5. Brundin P, Karlsson J, Emgård M, et al: Improving the survival of grafted dopaminergic neurons: a review over current approaches. Cell Transplant 9: 179-195, 2000.
6. Wagner JP, Black IB and DiCicco-Bloom E: Stimulation of neonatal and adult brain neurogenesis by subcutaneous injection of basic fibroblast growth factor. J Neurosci 19: 6006-6016, 1999.

7. Ramirez JJ, Finklestein SP, Keller J, Abrams W, George MN and Parakh T: Basic fibroblast growth factor enhances axonal sprouting after cortical injury in rats. Neuroreport 10: 1201-1204, 1999.

8. Yang H, Xia Y, Lu SQ, Soonq TW and Feng ZW: Basic fibroblast growth factor-induced neuronal differentiation of mouse bone marrow stromal cells requires FGFR-1, MAPK/ERK, and transcription factor AP-1. J Biol Chem 283: 5287-5295, 2008.

9. Caday CG, Klagsbrun M, Fanning PJ, Mirzabegian A and Finklestein SP: Fibroblast growth factor (FGF) levels in the developing rat brain. Brain Res Dev Brain Res 52: 241-246, 1990.

10. Shetty AK, Hattiangady B and Shetty GA: Stem/progenitor cell proliferation factors FGF-2, IGF-1, and VEGF exhibit early decline during the course of aging in the hippocampus: role of astrocytes. Glia 51: 173-186, 2005.

11. Jiang Y, Jahagirdar BN, Reinhardt RL, et al: Pluripotency of mesenchymal stem cells derived from adult marrow. Nature 418: 41-49, 2002.

12. Feeney DM, Boyeson MG, Linn RT, Murray HM and Dail WG: Responses to cortical injury: I. Methodology and local effects of contusions in the rat. Brain Res 211: 67-77, 1981.

13. Kawamata T, Dietrich WD, Schallert T, et al: Intracisternal basic fibroblast growth factor enhances functional recovery and up-regulates the expression of a molecular marker of neuronal sprouting following focal cerebral infarction. Proc Natl Acad Sci USA 94: 8179-8184, 1997.

14. Jin K, Sun Y, Xie L, et al: Neurogenesis and aging: FGF-2 and HB-EGF restore neurogenesis in hippocampus and subventricular zone of aged mice. Aging Cell 2: 175-183, 2003.

15. Raballo R, Rhee J, Lyn-Cook R, Leckman JF, Schwartz ML and Vaccarino FM: Basic fibroblast growth factor (Fgf2) is necessary for cell proliferation and neurogenesis in the developing cerebral cortex. J Neurosci 20: 5012-5023, 2000.

16. Monfils MH, Driscoll I, Vavrek R, Kolb B and Fouad K: FGF-2-induced functional improvement from neonatal motor cortex injury via corticospinal projections. Exp Brain Res 185: 453-460, 2008

17. Lu D, Mahmood A, Wang L, Li Y, Lu M and Chopp M: Adult bone marrow stromal cells administered intravenously to rats after traumatic brain injury migrate into brain and improve neurological outcome. Neuroreport 12: 559-563, 2001.

18. Mahmood A, Lu D, Lu M and Chopp M: Treatment of traumatic brain injury in adult rats with intravenous administration of human bone marrow stromal cells. Neurosurgery 53: 697-703, 2003.

19. Mahmood A, Lu D, Wang L, Li Y, Lu M and Chopp M: Treatment of traumatic brain injury in female rats with intravenous administration of bone marrow stromal cells. Neurosurgery 49: 1196-1204, 2001

20. Bondanelli M, Ambrosio MR, Margutti A, et al: Evidence for integrity of the growth hormone/insulin-like growth factor-1 axis in patients with severe head trauma during rehabilitation. Metabolism 51: 1363-1369, 2002

21. Winter CD, Pringle AK, Clough GF and Church MK: Raised parenchymal interleukin-6 levels correlate with improved outcome after traumatic brain injury. Brain 127: 315-320, 2004.

22. McIntosh TK, Saatman KE, Raghupathi R, et al: The Dorothy Russel Memorial Lecture. The molecular and cellular sequelae of experimental traumatic brain injury: pathogenetic mechanisms. Neuropathol Appl Neurobiol 24: 251-267, 1998.

23. McKay R: Stem cells in the central nervous system. Science 276: 66-71, 1997.

24. Ourednik J and Ourednik V: Graft-induced plasticity in the mammalian host CNS. Cell Transplant 13: 307-318, 2004.

25. Bracken MB, Shepard MJ, Holford TR, et al: Administration of methylprednisolone for 24 to 48 hours or tirilazad mesylate for 48 hours in the treatment of acute spinal cord injury. Results of the third national acute spinal cord injury randomized controlled trial. National Acute Spinal Cord Injury Study. JAMA 277: 1597-1604, 1997.

26. Bracken MB, Shepard MJ, Holford TR, et al: Methylprednisolone or tirilazad mesylate administration after acute spinal cord injury: 1-year follow-up. Results of the third National Acute Spinal Cord Injury randomized controlled trial. J Neurosurg 89: 699-706, 1998.

27. Liau LM, Bergsherder M and Becker DP: Pathology and pathophysiology of head injury. In: Neurological Surgery. Youmans JR (ed). 4th edition. WB Saunders, Philadelphia, pp1549-1594, 1996. 